The Labore Journal of Economics

Special Edition (September 2007)

\title{
Industrial Competitiveness of Pakistan (2000-10)
}

\section{A. R. Kemal*}

\section{Abstract}

Though Pakistan's exports have increased significantly, analyses have shown that Pakistan's industrial competitiveness is limited to a narrow range of products. This paper looks at the factors affecting Pakistan's competitiveness ranking and relates these various factors to trends in Pakistan's total factor productivity. In addition to looking at the components of Pakistan's competitiveness ranking, this paper details the steps required for Pakistan to increase its global industrial competitiveness.

\section{Introduction}

Whereas Pakistan's exports have increased from $\$ 8$ billion to $\$ 18$ billion over the last few years, the level of exports is still just a fraction of the exports of various South East Asian countries ${ }^{1}$. The low levels of Pakistan's exports may be attributed to its competitive edge in a few products and that, too, in low end technology products. Since the growth rate of exports has fallen to around 5\% during 2006-07 following the double digit but falling growth rates over the 2003-06 period, the formulation of a strategy for the growth of exports over the medium and long run has assumed great significance. It needs to be underscored that just the provision of subsidies or devaluation of the rupee can hardly result in a continuous increase in the export level. If the country has to be a major player in international trade it must enhance its competitiveness through improved levels of total factor productivity.

David Ricardo a couple of centuries back on the basis of a 2-country, 2-product and 1-production factor model had suggested that even if a country is inefficient in the production of both the goods, it would be able to compete in the world market as long as it specializes in accordance with its comparative advantage. The inefficiencies in production, however, would be counterbalanced by the low wage rates and the cost of production of the

\footnotetext{
* Former Director Pakistan Institute of Development Economics (PIDE), Islamabad.

${ }^{1}$ A few decades back their exports were lower than that of Pakistan.
} 
export product would be lower than that in the importing country. If the country improves the productivity levels, wages would rise without increasing the cost of production and jeopardizing the competitiveness.

Heckhsher-Ohlin suggests that the country would specialize in the activities that intensively use the abundant factor. They assumed the free availability of technology and no factor reversals but in practice neither is technology freely available nor is it the same across all the countries, and factor reversals do take place which may invalidate the theory. As the theory is based on factor endowments, any change in factor endowment would result in changes in comparative advantage over time. Moreover, in a seminal contribution, Professor Porter suggested that competitiveness may be derived from human resources and technological development resulting in innovation and reduction in the cost of production.

In recent years, a number of international agencies have ranked the competitiveness of each country on the basis of various indicators. The most important and oft quoted is the rankings by the Global Competitiveness Report of the World Economic Forum. For the last four years, it has also reported the competitiveness ranking of Pakistan, which falls below the median in most of the competitive indicators, indicating that Pakistan has to travel a long distance even to reach the average of the competitiveness indicators..

The Asian Development Bank and the World Bank have examined Pakistan's industrial competitiveness. The Asian Development Bank Report on industrial competitiveness prepared by Lall and Weiss (2004) examines various technology indices and classifies exports and value added in accordance with them. They conclude that Pakistan's competitiveness is not only restricted to a few products but that its competitiveness has also eroded over time. On the other hand, the World Bank's Report (2006) on growth and export competitiveness suggests that, despite some improvements, the country can attain an average growth rate of $8 \%$ only if there are improvements in almost all the competitive indicators including institutions, human resource development and technology. It also suggests policy measures through value chain analysis for the various export products of Pakistan.

Kemal, Muslehuddin, and Qadir (2002) examined the Revealed Comparative Advantage of Pakistan and found that it has a comparative advantage in only a small number of products that are resource based, or at the lower end of technology. Similarly, Kemal, Mahmood and Ahmad (1994) found Pakistan's comparative advantage in a narrow band of products, on the basis of Domestic Resource Cost. 
The country needs to improve its competitiveness in a large number of products and the present study examines the possibilities of enhancing competitiveness and the policies required for that. The plan of the paper is as follows: After this Introductory Section, the determinants of competitiveness and Pakistan's competitiveness ranking are reported in Section 2. The significance of total factor productivity and its growth in Pakistan is analyzed in Section 3. The measures required for improving the competitiveness are discussed in Section 4. Major conclusions and policy recommendations are summarized in the concluding section of the paper.

\section{Determinants of Competitiveness and Pakistan's Competitive Ranking}

Porter suggests that a country can develop competitiveness through the development of human resource activities including education, health, skills and technological development. The competitiveness is the ability of firms to compete with international firms of best practice. No doubt firms formulate and implement strategies to reduce the cost of production and improve the quality of products. However, due to market failures in various activities relating to competitiveness, government intervention becomes necessary. "The essence of a competitiveness strategy is to promote in-firms learning, skill development and technological effort, improve the supply of information, and coordinate collective learning processes that involve different firms in the same industry, or across related industries popularly known as 'clusters', geographic or activitywise" (See ADB, (2004)).

Competitiveness and comparative advantage do change over time due to various factors which include among others "rapid technical change, shrinking economic distance, technical progress in information processing, changes in the form of industrial organizations, development of value chains, development of clusters." The countries that develop technologies, access the markets, absorb and adapt the new technologies, and have an atmosphere that allows firms to move up the technological scale enhancing their competitiveness.

Pakistan ranks $91^{\text {st }}$ in the competitive index out of 125 countries included in the Global Competitive index and its score is 3.7 on the scale from 1 for the poorest rank to 10 for the highest rank. While Pakistan's score is poor, it is encouraging to note that the score has improved from 3.5 to 3.7 and the ranking from $94^{\text {th }}$ to $91^{\text {st }}$.

There are three sub-sectors of the Global Competitiveness Index, viz. basic requirements, efficiency enhancers and innovation factors. In all the 
three indicators, Pakistan lags behind the median except for the indicator measuring innovation factors where it is around the median (See Table-1). It suggests that Pakistan is far behind in competitiveness and if Pakistan has to grow at a rate of $8 \%$ on average as envisaged in the Medium Term Development Framework (MTDF), its score in almost all the indicators must improve significantly and it should be among the top 25 countries of the world (See World Bank (2006)).

Table-1: Global Competitiveness Index for Pakistan

\begin{tabular}{lcc}
\hline & Rank & Score \\
\hline 2006-07 & 91 & 3.7 \\
2005-06 & 94 & 3.5 \\
Basic Req. & $\mathbf{9 3}$ & $\mathbf{4}$ \\
1st pillar: Institutions & 79 & 3.5 \\
2nd pillar: Infrastructure & 67 & 3.4 \\
3rd pillar: macroeconomy & 86 & 4.2 \\
4th pillar: Health and Primary Education & 108 & 4.8 \\
Efficiency Enhancers & $\mathbf{9 1}$ & 3.3 \\
5th pillar: Higher Education and Training & 104 & 2.8 \\
6th pillar: Market Efficiency & 54 & 4.2 \\
7th pillar: Technological Readiness & 89 & 2.8 \\
Innovation Factors & $\mathbf{6 0}$ & 3.7 \\
8th pillar: Business Sophistication & 66 & 4 \\
9th pillar: Innovation & 60 & 3.3 \\
\hline
\end{tabular}

Source: Global Competitiveness Report 2006-07

Institutions are crucial for the growth process and Pakistan lags behind considerably in all the indicators relating to institutional development (See Table-2). While the institutions are also important for the indigenous investors, they are crucial for foreign private investment especially for the manufacturing sector. The government intends to implement second generation reforms but so far an improvement in this direction has been quite limited. Efforts in this direction shall have to be enhanced considerably. 
Table-2: Institutions

\begin{tabular}{lll}
\hline & Rank & Score \\
\hline Efficiency of corporate boards & 123 & 3.5 \\
Business cost of terrorism & 122 & 3.1 \\
Property rights & 95 & 3.7 \\
Reliability of police services & 85 & 3.5 \\
Ethical behavior of firms & 82 & 3.8 \\
Judicial independence & 80 & 3.3 \\
Business cost of crime and violence & 76 & 3.8 \\
\hline
\end{tabular}

Source: Global Competitiveness Report 2006-07

Inadequate and poor quality infrastructure increases transaction costs and erodes the competitive edge of industries. Over recent years there have been considerable improvements in infrastructure especially in the telecommunications sector, but that seems to not have found its way so far into the Global Development Report. Teledensity has improved considerably than that reported in Table-3, as it is now around 30 per 100 persons. Incorporating these developments would improve the ranking of Pakistan further; Pakistan has a reasonably good ranking in railroads, ports and air travel. However, it is the power supplies that pull down the ranking of Pakistan in terms of infrastructure.

Table-3: Infrastructure

\begin{tabular}{lll}
\hline & Rank & Score \\
\hline Overall infrastructure quality & 67 & 3.4 \\
Railroad infrastructure development & 39 & 3.6 \\
Quality of port Infrastructure & 52 & 3.8 \\
Quality of airport structures & 59 & 4.6 \\
Telephone lines & 101 & 3 \\
Quality of electricity supply & 87 & 3.5 \\
\hline
\end{tabular}

Source: Global Competitiveness Report 2006-07

Pakistan has done better in some indicators of market efficiency including number of days required to set up businesses, hiring and firing practices and taxation and loans. Moreover, even though its score in easy access to loans has been low, its ranking is quite good. But despite its score around 5 in ownership restrictions of foreign firms and soundness of banks, its rank is low. In other indicators Pakistan ranks poorly (See Table-4). 
Table-4: Market Efficiency

\begin{tabular}{lrr}
\hline & Rank & Score \\
\hline Efficiency of legal framework & 91 & 3 \\
Hiring and firing practices & 26 & 4.6 \\
Cooperation in labor-employer relations & 77 & 4.4 \\
Intensity of local competition & 73 & 4.6 \\
Brain drain & 73 & 2.9 \\
Foreign ownership restrictions & 72 & 4.9 \\
No. of procedures require to start a new business & 70 & 11 procedures \\
Time required to start a business & 30 & 24 days \\
Extent and effect of taxation & 33 & 3.9 \\
Soundness of banks & 84 & 5 \\
Ease of access to loans & 42 & 3.8 \\
\hline
\end{tabular}

Source: Global Competitiveness Report 2006-07

Technological capabilities are determined by education, training, scientific and technological infrastructure and they are reflected in the innovations and patents. Table- 5 shows various aspects of technological preparedness. The net enrolment rates at the primary and tertiary levels of education are $66.2 \%$ and $3.0 \%$ respectively, the poor quality of education and, except for market sophistication like value chains and local supplies, Pakistan ranks poorly in terms of technological development. 
Table-5: Education and Technical Capabilities

\begin{tabular}{lrr}
\hline & Rank & Score \\
\hline Primary enrolment & 112 & 66.2 \\
Tertiary enrolment & 106 & 3 \\
Extent of staff training & 91 & 3.1 \\
Quality of math and science education & 85 & 3.4 \\
Local availability of research and training services & 83 & 3.4 \\
Quality of the educational system & 74 & 3.2 \\
Cellular telephones & 115 & 3.3 \\
Personal computers & 113 & $0.4 / 100$ \\
Internet users & 107 & $131.1 / 100000$ \\
Technological readiness & 77 & 3.4 \\
FDI and technology transfer & 75 & 4.8 \\
Firm level technology absorption & 85 & 4.4 \\
Value chain presence & 47 & 4 \\
Local supplier Quantity & 61 & 4.7 \\
Local supplier Quality & 66 & 4.2 \\
Production process Sophisticate & 59 & 3.6 \\
Nature of Competitive Adv. & 54 & 3.5 \\
Availability of scientists and engineers & 78 & 4.7 \\
Utility patents & 78 & 29.2 \\
Capacity for innovation & 38 & -2 \\
Govt. procurement of technology products & 47 & 3.2 \\
Secondary Event & & 3.2 \\
Quality of public schools & 79 & \\
\hline
\end{tabular}

Source: Global Competitiveness Report 2006-07

\section{Trends in Total Factor Productivity in Pakistan}

It is generally believed that total factor productivity (TFP) in Pakistan has been small, but it has accounted for one-third of the growth for the period 1964-65 to 2000-01. TFP has grown at a rate of $1.66 \%$ for the entire economy, only $0.37 \%$ for agriculture but $3.21 \%$ for the manufacturing sector, accounting for about half of the growth in the sector. Nevertheless, 
while productivity growth is quite encouraging it needs to be noted that it reflects rather poor levels of productivity levels in the base year and has been just catching up through learning by doing. There has been hardly any growth in productivity arising from technological development and human resource development.

Table-6: Trends in Total Factor Productivity

\begin{tabular}{lcccc} 
& & \multicolumn{3}{c}{ (\%age Growth Rates) } \\
\cline { 3 - 4 } & \multirow{2}{*}{ GDP* } & \multicolumn{2}{c}{ Contribution of } & \multirow{2}{*}{ TFP } \\
\cline { 3 - 4 } & 5.31 & 2.48 & 1.17 & 1.66 \\
Overall & 3.89 & 2.70 & 0.82 & 0.37 \\
Agriculture & 6.39 & 2.23 & 0.94 & 3.21 \\
Manufacturing & & & & \\
Contribution to & & 46.62 & 22.12 & 31.26 \\
Aggregate Growth & & 69.33 & 21.11 & 9.57 \\
Agriculture Growth & & 34.99 & 14.74 & 50.27 \\
Manufacturing Growth & & &
\end{tabular}

Source: Kemal, Muslehuddin and Qadir (2002)

TFP growth in the manufacturing sector has shown wide variations. It has accounted for almost a $3 \%$ increase in output per annum in the 1960 s and 1980s, but it was quite low in the 1970s and in the 1990s. In the $1990 \mathrm{~s}$ it was just $0.78 \%$. However, in the manufacturing sector it was $1.64 \%$.

Table-7: Trends in Total Factor Productivity during 1990s (\%)

\begin{tabular}{|c|c|c|c|c|}
\hline \multirow[t]{2}{*}{ Sector } & \multirow[b]{2}{*}{ GDP } & \multicolumn{2}{|c|}{ Growth Rates } & \multirow[b]{2}{*}{ Residual } \\
\hline & & Capital & Labour & \\
\hline Overall & 4.41 & 2.38 & 1.25 & 0.78 \\
\hline Agriculture & 4.54 & 2.21 & 0.81 & 1.52 \\
\hline Manufacturing & 3.99 & 2.09 & 0.25 & 1.64 \\
\hline \multicolumn{5}{|l|}{ Contribution to } \\
\hline Overall Aggregate Growth & & 53.97 & 28.25 & 17.78 \\
\hline Agriculture Growth & & 48.63 & 17.83 & 33.55 \\
\hline Manufacturing Growth & & 52.54 & 6.26 & 41.20 \\
\hline
\end{tabular}

Source: Kemal, Muslehuddin and Qadir (2002). 


\section{Preparing for Technological Capabilities and Competitiveness}

The Medium Term Development Framework (MTDF) 2005-10 calls for a growth rate of $8.2 \%$ in 2010 , with an average growth rate of $7.6 \%$ over the 5 year period. It emphasizes improvements in the productivity levels by deploying knowledge inputs rather than focusing only on the accumulation of inputs. However, the MTDF neither provides for sufficient investment levels, nor for skill development and improvements in technological capabilities required to achieve the high growth rates envisaged in the MTDF.

Pakistan can realize the envisaged growth rates provided investment levels increase to $30 \%$ of GDP and total factor productivity increases through technological development and/or the adoption, adaptation and diffusion of new techniques. For an increase in investment and technological change the institutions, regulations, education, and technological personnel would have to increase and special efforts shall have to be mounted. A business friendly environment would foster both domestic and foreign investments resulting in both export competitiveness and diversification.

The World Bank (2006) suggests that if the quality of the investment environment in Pakistan matches that of the Shanghai investment climate, then the average productivity of Pakistan's textile firms operating in Karachi would improve by $81 \%$, the rate of return to capital would increase by $36 \%$, and wages would rise by $23 \%$. The increased profitability would encourage more investment and further improvement in competitiveness ${ }^{2}$. Technological capabilities develop slowly but once the process starts, it gains momentum and a virtual circle of growth, competitiveness and investment in new capabilities take place. This in turn helps in further technological capabilities and growth. On the other hand, if the economy is stuck in a low level equilibrium trap and is unable to fund technological development, it is caught in a vicious circle. However, it can break out of this circle through a concerted strategy by improving the human capital and technological base and improving the institutions and infrastructure.

The essence of the competitiveness strategy is to improve the supply of information, skills and technology and encourage firms to make an effort at the learning of skills and the adoption and adaptation of technology. Over the last couple of decades there have been rapid technological changes

\footnotetext{
${ }^{2}$ It also suggests that reforms carried out by Pakistan have been mainly responsible for the high growth rate of per capita incomes in Pakistan in recent years.
} 
across the globe which has rendered the old technologies obsolete even in the low wage economies ${ }^{3}$.

New technologies are not just new products and processes, but involve the firms supply chain, human resource development, technology linkages etc. It amounts to building new capabilities and promoting structural change in the production patterns, the upgrading of technologies in activities including finding new markets and marketing niches. Various industries may need to access, adapt, and add new technologies to remain competitive. Industrial leaders have to invest in technological innovations while the followers invest in absorbing and adopting the technology. Contrary to the general impression that the latter is easy, it needs to be noted that it is a complex process and involves the development of skills and technological personnel. The technical change affects all industries though they are more important in innovation-based industries ${ }^{4}$.

While technological development is absolutely necessary the capacity development for technological change is slow, costly and a risky learning process. The critical factor is not just addition to capacities but the ability to understand how to operate these at the optimum levels given local conditions and factor endowments and to upgrade the technologies to lower the cost of production and evolve new products.

It also needs to be noted that the competitiveness of a country undergoes changes in response to innovation and the relocation of processes or functions. The improvements in productivity do not necessarily involve innovation, but could involve the efficient use of existing technologies. The reduction in the dispersion of the use of technology across different firms through the diffusion of technology helps in improving the productivity levels of an industry. However, it may involve large amounts of investment, effort, time, risk and constrained interaction with other actors with whom information and skills are shared.

In most developing countries, firms are not aware of how to upgrade their technologies to the best practice levels. In general they fail to understand what new skills, technical knowledge and organizational techniques are generally available and how these can be accessed. Cooperation with other firms or institutions requires efforts in over-coming problems of linkage. Cluster development can be useful in this direction.

\footnotetext{
${ }^{3}$ The enterprises had to use new technology to remain viable.

${ }^{4}$ Such industries have grown at double the rate compared to the other industries.
} 
Lack of skilled manpower is a major constraint to business activities in Pakistan and is critical to improving the productivity and competitiveness of Pakistani firms. With a view to improving education and skills, merely higher allocations to education and skill activities would not be sufficient, though it is absolutely necessary. Governance needs to be improved through the strengthening and ensuring of more effective recruitment, management and performance of teachers keeping in mind their competencies and absenteeism. It would help in the completion of education. Similarly, skill development calls for improved syllabi, teachers and laboratories and all the governance issues discussed in terms of education. Moreover, it needs to be ensured that intermediate and secondary education is more purposeful and linked to the economy and the changing needs of the labor market and careers. It also implies an upgradation and expansion of vocational and technical education capacity to train individuals who are completing matriculation, drop outs and the unemployed.

Whereas there have been significant improvements in the cost of doing business indicators over the last few years, the cost is still quite high. Corruption continues to be very high. The regulatory environment leaves much to be desired in all aspects of commercial laws and regulations. There is a need for operational rules, procedures and a monitoring system which are universally implemented. There is a need to develop a dispute resolution system for commercial adjudication outside courts. The infrastructure leaves much to be desired. In the power sector there are difficulties in obtaining electricity connections and the supply is unreliable, thus placing an enormous burden on business. The financial sector reforms need to be consolidated and expanded. The legal framework and judicial processes need to be improved.

Despite improvements in recent years, major problems in transport logistics remain. Long standing problems include the old and depleted conditions of the transport fleet, serious overloading of trucks, restrictions on the provision of bonded transport and the high cost for less than container load shipments. Pakistan Railways do not operate on a commercial basis and gives priority to passengers rather than cargo. The main problem at the ports is the congestion at the terminals and the turnaround time of ships is quite high. Pakistan lacks a coherent strategy for quality and SPS management in relation to its trade. Pakistan needs to better define and demarcate the role and responsibilities of different agencies, strengthen existing technical capacities for administrating science based SPS measures, and institutionalize and early warning or surveillance system for pest and disease contaminants etc. 


\section{Conclusions}

Pakistan's exports, despite a sharp increase in recent years, are just a fraction of the exports of various South East Asian countries and the main factor behind the low level of exports is the lack of competitiveness and comparative advantage in limited products the demand for which is growing slowly in the world market. Exporters are once again asking for more subsidies and devaluation of the rupee rather than enhancing their competitiveness through improvement in total factor productivity. Competitiveness may be enhanced through the development of human resources including skills and technological development. If Pakistan wants to accelerate its GDP growth rate to around $8 \%$, it will have to improve its ranking from $91^{\text {st }}$ in the world.

Whereas total factor productivity over the long run in the industrial sector has contributed one-half to the growth, its contribution has fallen in the $1990 \mathrm{~s}$ to just $0.8 \%$. Moreover, improvements reflect low levels of productivity in the base year and they reflect just catching up through learning by doing and there has hardly been any growth in productivity arising from technological development and human resource development. Efforts need to be mounted to improve the skills and technological infrastructure in the country as has been suggested in the MTDF - that growth would be realized by deploying knowledge inputs.

Whereas there have been significant improvements in the cost of doing business indicators over the last few years, the cost is still quite high. Corruption continues to be very high. The regulatory environment leaves much to be desired in all aspects of commercial laws and regulations. The infrastructure leaves much to be desired. In the power sector there are difficulties in obtaining electricity connections and the supply is unreliable, thus placing an enormous burden on the business sector. Financial sector reforms needs to be consolidated and expanded. The legal framework and judicial processes need to be improved. 


\section{References}

Kemal, A. R., Musleh-ud Din, Kalbe Abbas and Usman Qadir, 2002, "A Plan to Strengthen Regional Trade Cooperation in South Asia" in T. N. Srinivasan (ed.) Trade Finance and Investment in South Asia, Social Science Press, New Delhi,

Kemal, A.R., 2002, "Productivity Growth during the 1990s in Pakistan," Asian Productivity Organization, Japan.

Kema1, A.R., Muslehuddin and Usman Qadir, 2005, "Exports and Economic Growth in South Asia" in Mohsin Khan (ed.) Economic Development in South Asia, New Delhi: Tata McGraw-Hill Publishing Company Ltd.

Kemal, A.R., Zafar Mahmood and Athar Maqsood Ahmad, 1994, Structure of Protection, Efficiency, and Profitability. Islamabad, Study prepared for the Resource Mobilization and Tax Reforms Commission, Karachi.

Lall, Sanjay A. and Jonh Weiss, 2004, Industiral Competitiveness: The Challenge for Pakistan, ADB, Islamabad.

World Bank, Pakistan: Growth and Export Competitiveness, 2006.

World Economic Forum, The Global Competitive Report 2006-07, Geneva. 